\title{
Mithrax hispidus (Herbst) e Mithrax tortugae Rathbun novos registros de Brachyura (Decapoda, Majidae) para o litoral de Santa Catarina, Brasil
}

\author{
Paulo Juarez Rieger ${ }^{1}$ \\ Jackson L.B. Giraldi ${ }^{2}$
}

\begin{abstract}
Mithrax hispidus (Herbst) and Mithrax tortugae Rathbun new records of Brachyura (Decapoda, Majidae) to the seaboard of Santa Catarina, Brazil. They are registered for the first time in the South Brazilian coast, the crabs Mithrax hispidus (Herbst, 1790) and Mithrax tortugae Rathbun, 1920, which previous Southern limit of distribution were at São Paulo State and now it is extended to the Santa Catarina State coast line.

KEY WORDS. Decapoda, Mithrax hispidus, Mithrax tortugae, Santa Catarina, new records
\end{abstract}

A família Majidae contém aproximadamente 900 espécies distribuídas em regiões marinhas. A vasta maioria das espécies são pequenas e não têm importância econômica, mas servem de alimento para peixes (PROVENZANO \& BROWNELL 1977).

De acordo com Melo (1996), na costa brasileira a família Majidae está representada por 45 gêneros que abrigam 81 espécies. No litoral brasileiro, o gênero Mithrax é representado pelas espécies: Mithrax verrucosus H. Milne Edwards, 1832; Mithrax besnardi Melo, 1990; Mithrax hemphilli Rathbun, 1892; Mithrax braziliensis Rathbun, 1892; Mithrax caribbaeus Rathbun, 1920; Mithrax hispidus (Herbst, 1790) e Mithrax tortugae Rathbun, 1920.

Mithrax hispidus caracteriza-se por apresentar carapaça irregular, bastante mais larga do que longa. Tubérculos gástricos pouco salientes, fronte larga, com processo rostrais curtos, separados por sinus em forma de "U". Segmento basal da antena com dois dentes, sendo que o mais interno quase alcança a linha do rostro. Órbita com quatro tubérculos na margem. Margem lateral com cinco dentes espiniformes, o primeiro obtuso, às vezes bífido na extremidade; o segundo mais longo e duplo, curvado para a frente; terceiro e quarto mais delgados e quinto, na margem pósterolateral, muito menor. Região sub-hepática com dois tubérculos. Região pterigostomial com vários tubérculos. Mero do quelípodo com quatro ou cinco espinhos na face superior. Carpo liso. Um forte dente na base do dátilo (MELo 1996).

Mithrax tortugae caracteriza-se por apresentar carapaça mais larga do que longa. Regiões cardíaca e gástrica bem delineadas. Largura anterior da região gástrica o dobro da largura posterior. Região mesogástrica com fileira de cinco tubérculos

1) Laboratório Zoologia de Crustáceos Decapodos, Departamento de Ciências MorfoBiológicas, Fundação Universidade Federal do Rio Grande. Caixa Postal 474, 96201-900 Rio Grande, Rio Grande do Sul, Rio Grande do Sul, Brasil.

E-mail: dmbpjr@super.furg.br

2) Bolsista de Iniciação Científica FAPERGS/FURG. 
(inconspícuos nos adultos). Região meso-branquial com três tubérculos. Margem ântero-lateral com quatro lóbulos, não incluindo o orbital externo. Último lóbulo ântero-lateral dirigido para frente. Processos rostrais curtos e separados por sinus em forma de "V". Órbitas circulares e com dois pequenos tubérculos na margem superior. Margem interna do isquiopodito do terceiro maxilípodo espinulada e pilosa. Mero do quelípodo tuberculado na fase dorsal e com dois fortes tubérculos na face interna. Dátilos das patas ambulatórias pilosos (MELO 1996).

Com a presente nota, fica registrada para o litoral catarinense a presença do gênero Mithrax com as espécies Mithrax hispidus e Mithrax tortugae, cujas distribuições geográficas anteriores tinham como limite sul o Estado de São Paulo (MELO 1996).

Os exemplares das espécies Mithrax hispidus e Mithrax tortugae foram amostrados na região costeira do município de Bombinhas, Santa Catarina, nas praias de Retiro dos Padres e Ponta da Sepultura, situadas no trecho do litoral catarinense compreendido entre as latitudes $27^{\circ} 06^{\prime} 00^{\prime \prime}$ S (Ponta de Porto Belo) e $27^{\circ} 13^{\prime} 00^{\prime \prime}$ S (Ponta de Zimbros). As amostragens foram realizadas através de mergulhos autônomos efetuados junto à Ponta da Sepultura e ao Costão de Retiro dos Padres, nos meses de outubro e novembro de 1995.

Foram coletados: 14 exemplares de Mithrax hispidus sendo 10 machos com o peso compreendido entre 36.3 a $560.0 \mathrm{~g}$, largura da carapaça entre 5,6 a $12,9 \mathrm{~cm}$ e comprimento da carapaça entre 9,3 a $4,4 \mathrm{~cm} ; 4$ fêmeas ovígeras com o peso compreendido entre 105,0 a 130,0 g, largura da carapaça entre 9,7 a 8,3 cm e comprimento da carapaça entre 7,1 a 6,3 cm; 2 exemplares machos de Mithrax tortugae com o peso compreendido entre 2,5 a 7,4g, largura da carapaça entre 2,8 a $3,3 \mathrm{~cm}$ e comprimento da carapaça entre 2,7 a $2,8 \mathrm{~cm}$.

O material analisado está depositado na Coleção Científica do Laboratório de Zoologia de Crustáceos Decápodos do Departamento de Ciências Morfobiológicas da Fundação Universidade do Rio Grande, Rio Grande, Rio Grande do Sul, lotes de $n^{\circ}$ 692 e 693 de Mithrax tortugae e de n 605,672 e 729 para Mithrax hispidus.

AGRADECIMENTOS. Agradecemos ao Prof. Dr. Gustavo Schmidt de Melo (Museu de Zoologia da Universidade de São Paulo) pela identificação das espécies.

\section{REFERÊNCIAS BIBLIOGRÁFICAS}

Melo, G.A.S. 1996. Manual de Identificação dos Brachyura (Caranguejos e Siris) do Litoral Brasileiro. São Paulo, Ed. Plêiade, 603p.

- 1998. Malacostraca - Eucarida. Brachyura. Oxyrhyncha and Brachyrhyncha, p. 455-515. In: P.S. Young (Ed.). Catalogue of Crustacea of Brazil. Rio de Janeiro, Museu Nacional, Série Livros $6,717 \mathrm{p}$.

Provenzano, A.J. \& W.N. Brownell. 1977. Larval and early post-larval stages of the West Indian spider crab, Mithrax spinosissimus (Lamarck) (Decapoda: Majidae). Proc. Biol. Soc. Wash. 90 (3): 735-752.

Recebido em 27.IV.2000; aceito em 08.VI.2001. 